\title{
Pensar e viver a História nas fronteiras \\ Os jovens, a história (ensinada) e as imagens sobre o continente americano no contexto mato-grossense
}

\author{
Renilson Rosa Ribeiro \\ Luís César Castrillon Mendes \\ Osvaldo Rodrigues Junior
}

\section{SciELO Books / SciELO Livros / SciELO Libros}

RIBEIRO, R.R., MENDES, L.C.C., and RODRIGUES JUNIOR, O. Pensar e viver a História nas fronteiras: Os jovens, a história (ensinada) e as imagens sobre o continente americano no contexto mato-grossense. In: CERRI, L.F., ed. Os jovens e a História: Brasil e América do Sul [online]. Ponta Grossa: Editora UEPG, 2018, pp. 259-275. ISBN: 978-85-7798-248-6.

https://doi.org/10.7476/9788577982486.0011.

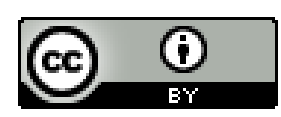

All the contents of this work, except where otherwise noted, is licensed under a Creative Commons Attribution $\underline{4.0 \text { International license. }}$

Todo o conteúdo deste trabalho, exceto quando houver ressalva, é publicado sob a licença Creative Commons Atribição 4.0. 


\section{PENSAR E VIVER A HISTÓRIA NAS FRONTEIRAS: OS JOVENS, A HISTÓRIA (ENSINADA) E AS IMAGENS SOBRE O CONTINENTE AMERICANO NO CONTEXTO MATO-GROSSENSE}

Renilson Rosa Ribeiro

Luís César Castrillon Mendes

Osvaldo Rodrigues Junior

"Nada do que um dia aconteceu pode ser considerado perdido" (Benjamin, 1985, p. 223)

\section{COMPLEXIDADES DO CAMPO: A HISTÓRIA ENSINADA ARTICULADA AO OFÍCIO DO HISTORIADOR}

A ação docente na área das Ciências Humanas torna-se cada vez mais uma atividade complexa e desafiadora. Complexa pela diversidade teórica e metodológica inerente ao campo; desafiadora por não se restringir apenas a uma mera transmissão do conhecimento, mas disponibilizar-se para melhoria qualitativa da sociedade. Assim, espera-se que as disciplinas constituintes desta área possibilitem leituras e interpretações de mundo, de forma a propiciar intervenções na vida prática.

No caso específico da História, disciplina que desde sua criação buscou legitimar Estados nacionais, a partir dos anos finais do Setecentos, possui uma peculiaridade adicional, na medida em que pode analisar, além de sincronicamente, os acontecimentos em uma perspectiva diacrônica. Desta forma, seu ensino exige maior capacidade de abstração por parte dos alunos, uma vez que o passado distante pode, também, ser o seu objeto de estudo.

Fazer viagens no tempo, ou seja, abstrair-se do tempo presente, contemporâneo, cotidiano, não é tarefa das mais exequíveis, principalmente por estarmos imersos em um regime de historicidade presentista, nos termos de François Hartog (2014). É natural o desinteresse em estudar algo localizado distante, tanto temporal quanto geograficamente da realidade do estudante. Se esse (ultra)passado acontecimento datado temporalmente, estranho e esquisito torna-se incompreensível, é porque talvez ele esteja 
desarticulado dos interesses, anseios e problemas da contemporaneidade vivida pelo aprendiz da História.

Torna-se descabida qualquer abordagem de conteúdo em sala de aula, seja qual nível for, desancorada nos problemas sociais, políticos, culturais, emocionais e econômicos do tempo presente, principalmente os que vão interferir diretamente na vida futura dos estudantes. Assim, assuntos como a crise política, econômica, moral e ética, tão característica em nosso país na atualidade, não podem ser excluídos das salas de aula. Iniciativas como Escola Sem Partido e as reformas propostas pela Base Nacional Curricular Comum (BNCC) e a Reforma do Ensino Médio podem (e devem) servir de exemplo para a articulação com outras medidas, em tempos pretéritos, que estabelecem estreitas relações e revelam contextos, muitas vezes, parecidos.

Uma incursão na História a contrapelo, como queria Walter Benjamim (1985), pode ser uma interessante e eficaz maneira de fazer com que o aluno tenha consciência de seu papel enquanto agente histórico, capaz de ler criticamente o mundo com a capacidade de modificá-lo qualitativamente. Nisto reside, a nosso ver, reside a importância da História e outras disciplinas afins: a capacidade para a formação da cidadania, na acepção plena do termo. E o que seria esta acepção plena? Certamente a resposta convergirá para outras respostas a outros questionamentos, tais como: quais concepções de História e cidadania estamos tentando forjar? Qual o sentido de se ensinar História nos dias atuais? Qual o seu valor? Quem são os agentes de minhas narrativas e das minhas aulas? Quais eventos eu seleciono e como são selecionados? O que estabelecem os currículos e a legislação vigente? As novas demandas sociais, os agentes historicamente silenciados, discriminados ou estereotipados nas narrativas estão se fazendo presentes? Nós, enquanto professores/historiadores, permitimos que eles saiam dos bastidores e assumam seus papéis de protagonistas?

Este artigo tem por objetivo analisar as ideias históricas de estudantes do Ensino Médio, em escolas públicas e privadas do estado de Mato Grosso, que vivem em regiões fronteiriças, no sentido de perceber de que forma eles elaboraram suas imagens sobre a História enquanto disciplina escolar e sobre a chamada História da América, enquanto partes constituintes da sua consciência histórica. 


\section{VIVENDO NAS FRONTEIRAS DO TEMPO: ENTRE A BRECHA TEMPORAL E O ETERNO PRESENTE}

De acordo com Luis Fernando Cerri (2011), os debates acerca da consciência histórica mobilizaram diversos autores, que apresentam distintas compreensões desse fenômeno humano. A principal divergência consiste no entendimento da consciência histórica enquanto algo próprio da condição humana, ou como atributo de uma parcela específica da sociedade.

Raymond Aron, na obra Dimensiones de la conciencia histórica (1962), defende que toda a sociedade é portadora de uma consciência histórica, mas que a sociedade europeia é a que tem uma consciência propriamente histórica. Partindo de uma perspectiva eurocentrada, Aron observa que "son los europeos los que han dado a los hindues la conciencia de su pasado. Es la historia científica, tal como practicaron los europeos, la que provee a los japoneses cultivados de la interpretación de su pasado" (ARON, 1962, p. 73).

Em direção semelhante, o filósofo Hans-Georg Gadamer afirma que "a consciência histórica que caracteriza o homem contemporâneo é um privilégio" (GADAMER, 1998, p. 17). Desta forma, ele define que a consciência histórica seria um estágio a ser atingido por alguns grupos sociais, o que condenaria os países periféricos a inconsciência histórica. Na compreensão deste autor, a relação entre a ciência especializada e o conhecimento de massas ocorreria apenas através das instituições de divulgação.

Outro autor a tratar da questão foi Philippe Ariès (1989), que indica que "[...] no antigo regime a consciência da história pouco existia, enquanto que na nossa época ela constitui o denominador comum das nossas sensibilidades. Assim, a ausência ou a presença de um passado particular distingue duas maneiras de se estar na história" (ARIÈS, 1989, s/p).

Desta forma, Aron (1962), Gadamer (1998) e Ariès (1998) identificam a consciência histórica enquanto um estágio ou privilégio de uma parcela da sociedade, mas especificamente do homem europeu moderno.

Agnes Heller (1993) e Jörn Rüsen(2001) entendem a consciência histórica como um fenômeno humano. Isto significa que, para eles, ela é fruto das condições de pensamento e não está restrita a grupos sociais 
específicos. Portanto, a consciência histórica seria "[...] toda produção de conhecimento que envolva indivíduos e coletividades em função do tempo" (CERRI, 2011, p. 28).

Heller (1993), na obra Uma Teoria da História, indica que,

[...] a consciência histórica é inerente ao estar no mundo (desde a percepção da historicidade em si mesmo, que se enraíza na ideia de que alguém estava aqui e não está mais, e de que eu estou aqui, mas não estarei um dia) e é composta por diversos estágios, que indicam a inserção da consciência em diferentes contextos da trajetória da humanidade (HELLER, 1993, p. 28).

Para Rüsen (2001), o homem deve agir intencionalmente no mundo e só pode fazer isso ao interpretá-lo e interpretar a si mesmo. Assim, tanto Heller quanto Rüsen entendem "que o pensar historicamente é um fenômeno, antes de qualquer coisa, cotidiano e inerente à condição humana" (CERRI, 2011, p. 29).

Sobre isso, Rüsen (2001, p. 78) afirma que "a consciência histórica não é algo que os homens podem ter ou não - ela é algo universalmente humano, dada necessariamente junto com a intencionalidade da vida prática dos homens". Logo, ele a define como "a soma de operações mentais com as quais os homens interpretam sua experiência da evolução temporal de seu mundo e de si mesmos, de forma tal que possam orientar, intencionalmente, sua vida prática no tempo" (RÜSEN, 2001, p. 57).

A aprendizagem histórica é o "[...] processo de mudança estrutural da consciência histórica" (RÜSEN, 2010, p. 51), que permite aos sujeitos não apenas adquirir ou ampliar o seu conhecimento do passado, mas mudar as formas como tratamos e utilizamos esse conhecimento. Tais formas, no entender de Rüsen (2010), podem variar dos modos tradicionais aos genéticos, passando pelo exemplar e crítico.

A formação histórica, entendida como "o conjunto das competências de interpretação do mundo e de si próprio, que articula o máximo de orientação do agir com o máximo de autoconhecimento, possibilitando assim o máximo de autorrealização ou de reforço identitário" (RÜSEN, 2007, p. 95), é responsável pela articulação entre as formas e os conteúdos históricos e os seus usos práticos. 
Destarte, há uma relação explícita entre as categorias consciência histórica, aprendizagem histórica e formação histórica no pensamento ruseniano. A consciência histórica é compreendida como uma ocorrência habitual da vida humana, que permite aos homens e mulheres orientar temporalmente as suas vidas. Essa consciência sofre alterações estruturais estimuladas pela aprendizagem histórica, enquanto processo de formação histórica, que possibilita o reforço identitário, permitindo aos sujeitos interpretarem o mundo e se autocompreenderem.

Algumas pesquisas empíricas intencionaram captar a consciência histórica. Youth and History, projeto liderado por Magne Angvik e Bodo von Borries (1997), contou com a participação de jovens de 15 anos de 25 países europeus, mais Israel e Palestina, no total de 32 mil entrevistados. Dentre os resultados destaca-se que "a influência do professor de história sobre as opiniões históricas do aluno é, no mínimo, limitada, como também é limitada a influência dos currículos oficiais de história sobre o trabalho do professor e seu resultado" (CERRI, 2011, p. 44).

Desde 2006, um projeto semelhante, intitulado Jovens e a História no Mercosul, vem acontecendo, organizado por pesquisadores brasileiros, argentinos e uruguaios. De acordo com Wilian Barom (2016), este projeto trata-se de, [...] um levantamento sobre a consciência histórica, cultura política e percepções da aprendizagem escolar de História de jovens entre 15 e 16 anos na América do Sul (Brasil, Argentina, Paraguai, Chile, Uruguai). Esta coleta de dados foi feita por meio de questionários impressos, para professores e alunos, em uma sala de aula por escola, em sete tipos de escolas (Pública de excelência, pública de periferia, pública rural, pública central, privada laica empresarial, privada laica comunitária e privada confessional). O que resultou num montante de 3246 questionários aplicados a alunos e 267 a professores. Com esta aplicação concluída em 2013, pesquisadores iniciaram um processo de análise destes dados, gerando inúmeras publicações científicas (BAROM, 2016, p. 71).

Este artigo, sem a pretensão de esgotar o tema, se propõe a contribuir para o conjunto de trabalhos que vêm analisando os dados obtidos no projeto. O objetivo foi averiguar o interesse dos jovens mato-grossenses pela história regional e dos demais países latino-americanos. A localização geográfica fronteiriça dos municípios pesquisados foi considerada 
na construção da hipótese de pesquisa, qual seja, a de que os jovens de Mato Grosso apresentam maior interesse pela história regional e latino-americana.

\section{HISTÓRIA E INTERVENÇÃO NA VIDA PRÁTICA: AS IMAGENS DA/NA FRONTEIRA A PARTIR DA ANÁLISE DOS DADOS}

Entre os anos de 2011 e 2012 foi aplicado um questionário composto por quarenta e três (43) questões para quatrocentos e quarenta e nove (449) estudantes de quinze (15) e dezesseis (16) anos de escolas públicas e privadas de Ensino Médio de três cidades do Estado de Mato Grosso Cáceres, Cuiabá (capital) e Rondonópolis, sendo cento e cinquenta e um (151) estudantes de Cáceres, cento e trinta e cinco (135) de Cuiabá e cento e sessenta e três (163) de Rondonópolis. Para a realização da referida pesquisa, foram envolvidos os pesquisadores e bolsistas ligados aos Departamentos de História da Universidade Federal de Mato Grosso (UFMT), do campus de Cuiabá e Rondonópolis, e do Curso de História da Universidade do Estado de Mato Grosso (UNEMAT), campus de Cáceres.

Dentre as questões, analisamos comparativamente a de número 18. Qual seu interesse sobre a história dos seguintes lugares, com destaque para as letras b. A história da minha região, e d. Outros países da América Latina. A opção por essa questão foi fruto da problemática da pesquisa acerca do interesse dos jovens mato-grossenses pela história regional e latino-americana.

$\mathrm{Na}$ letra b, identificamos os seguintes resultados (gráfico 1). 
Gráfico 1 - Comparação da distribuição das respostas dos estudantes das amostras brasileira e de cidades do Mato Grosso à questão 18b. Qual o seu interesse pela história dos seguintes lugares: a história da minha região, em porcentagens

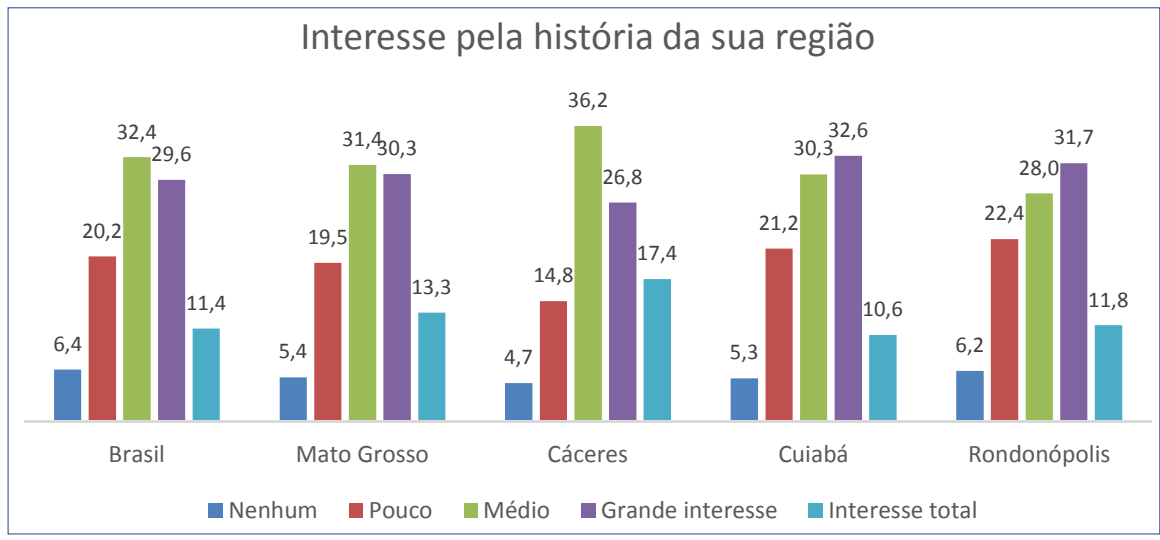

Fonte: Projeto Jovens e a História (2013). Elaboração dos autores.

Cáceres destaca-se por ter maior porcentagem de estudantes que demostra interesse total (17,45\%) pelas temáticas afeitas à História Regional, quando comparado com Cuiabá e Rondonópolis (principalmente entre os que demonstram interesse total - 10,61\% e 11,80\%, respectivamente). Se convertemos as respostas em uma escala que vai de -2 (nenhum interesse) a 2 (interesse total), as médias por cidade ficam assim: Cáceres tem a maior média (0,38), seguida de Cuiabá $(0,22)$ e Rondonópolis $(0,2)$. A distribuição da amostra de Mato Grosso, sem desagregação por cidade, apresenta 13,39\% de interesse total e 30,32\% de grande interesse, o que difere entre $1,5 \%$ e $2,0 \%$ das frequências da amostra do Brasil. Isto indica que, embora apareçam pequenas variações ocasionais, elas ocorrem em uma faixa muito restrita, dentro do desvio padrão da amostra nacional brasileira, sempre próximo a 1,0. Tem-se, portanto, um indicativo de que as amostras por cidade do Mato Grosso são consistentes com a amostra nacional (cuja média para a questão é de 0,19), sem apresentar diferenças acentuadas

O gráfico 2 oferece um parâmetro para comparação com as distribuições dos demais países da América do Sul selecionados para amostras da pesquisa. 
Gráfico 2 - Comparação da distribuição das respostas dos estudantes dos demais países da América do Sul à questão 18b. Qual o seu interesse pela história dos seguintes lugares: a história da minha região, em porcentagens

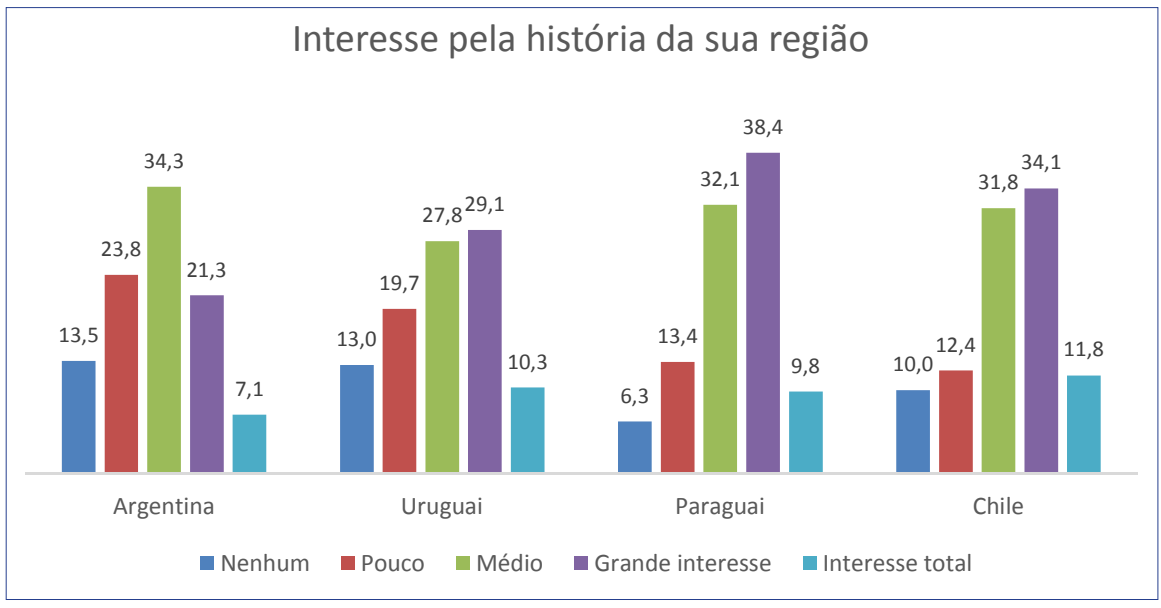

Fonte: Projeto Jovens e a História (2013). Elaboração dos autores.

Em relação aos demais países da América do Sul, o Chile destaca-se por ter uma maior porcentagem de estudantes que demostra interesse total $(11,8 \%)$ pelas temáticas afeitas à História Regional, uma leve vantagem sobre o Uruguai (10,3\%), o Paraguai (9,8\%), e a Argentina ocupa a última posição (7,1\%). Se compararmos à média do Brasil (11,4\%), observamos certa regularidade para baixo, no interesse total dos jovens pela História Regional na América Latina. Quando comparados os dados dos países da América Latina com os municípios de Mato Grosso, observa-se, também, certa regularidade no pouco interesse pelas temáticas regionais, com pequena diferença para Cáceres (17,4\%), 6\% acima da média nacional, 4,1\% da média estadual e 5,6\% acima da média chilena, a maior dentre os demais países da América Latina. Quando comparado ao dado da Argentina, a diferença sobe consideravelmente (10,3\%).

Com relação ao interesse dos estudantes nos outros países da América Latina, chegamos aos dados apresentados no gráfico 3. 
Gráfico 3 - Comparação da distribuição das respostas dos estudantes das amostras brasileira e de cidades do Mato Grosso à questão 18d. Qual o seu interesse pela história dos seguintes lugares: outros países da América Latina, em porcentagens

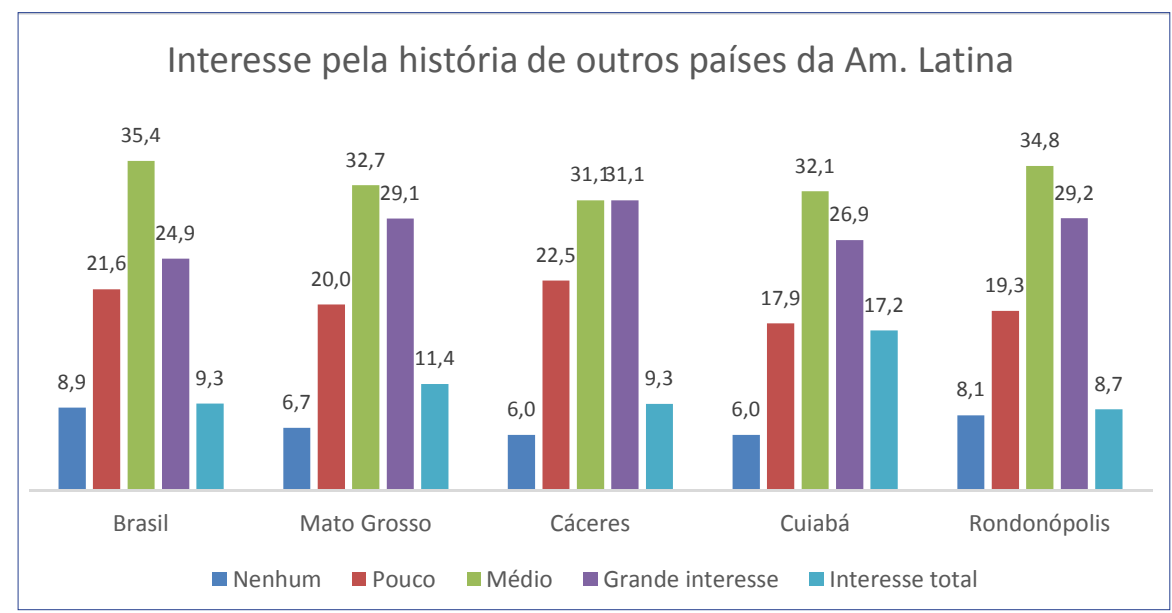

Fonte: Projeto Jovens e a História (2013). Elaboração dos autores.

No caso da apreciação do interesse pela história latino-americana, as amostragens de Mato Grosso registram, entre os estudantes, as médias de $29,1 \%$ de grande interesse e $11,4 \%$ de interesse total, o que, neste caso, difere aproximadamente entre 3,5\% e 4,0\% da amostra do Brasil. Merecem destaque, dentro do cenário mato-grossense, os dados de Cuiabá, que apontam que $17,2 \%$ dos estudantes têm interesse total pela temática, e 26,9\%, grande interesse. As amostras de Cáceres têm, respectivamente, $9,3 \%$ e $31,1 \%$. No caso de Rondonópolis, identificamos uma diferença da porcentagem do interesse total, quando comparado com Cuiabá: 8,70\%. Novamente, se trabalhamos com as médias aritméticas de cada município em questão, temos a confirmação de que o interesse por este recorte geográfico é levemente maior na capital do estado: 0,31 para Cuiabá, enquanto temos 0,15 em Cáceres e 0,11 em Rondonópolis. 
Gráfico 4 - Comparação da distribuição das respostas dos estudantes dos demais países da América do Sul à questão $18 \mathrm{~d}$. Qual o seu interesse pela história dos seguintes lugares: outros países da América Latina, em porcentagens

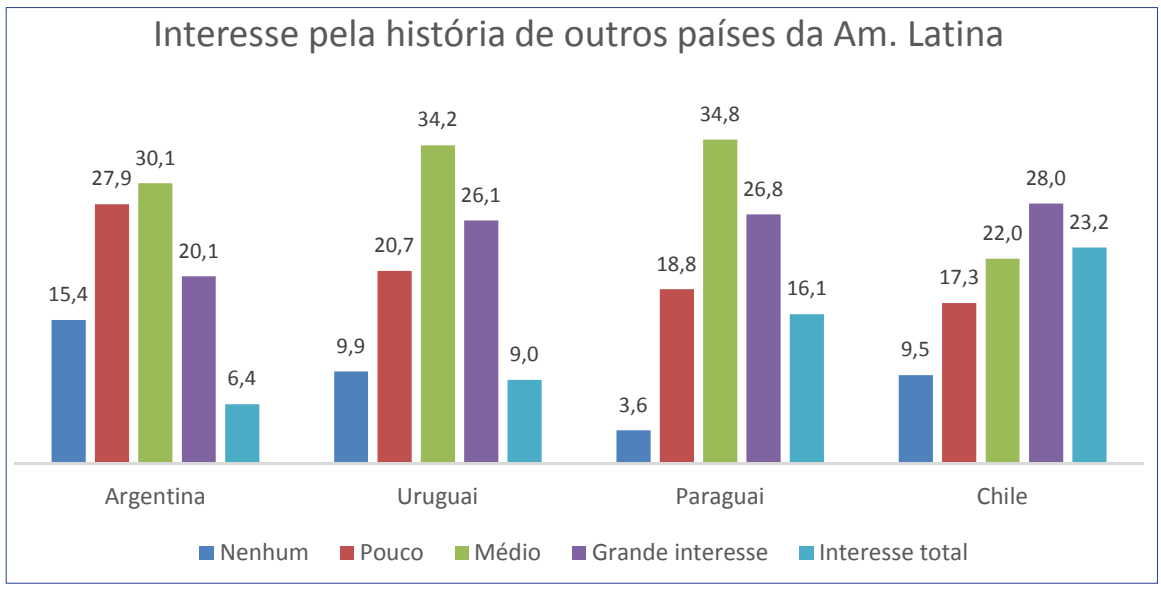

Fonte: Projeto Jovens e a História (2013). Elaboração dos autores.

No que se refere ao interesse pela história latino-americana nos demais países investigados, as amostragens novamente indicam o Chile $(23,2 \%)$ com o maior interesse total, seguido pelo Paraguai (16,1\%), Uruguai $(9,0 \%)$ e Argentina (6,4\%). Quando comparados aos dados de Mato Grosso, observa-se uma variação negativa de $11,4 \%$ no caso do Chile, e $4,7 \%$ para o Paraguai; e 2,4\% e 5\% positiva em relação a Uruguai e Argentina, respectivamente. Se comparamos o caso chileno ao brasileiro $(13,9 \%)$ e mato-grossense (11,8\%), novamente observamos o baixo interesse dos jovens pela história dos demais países da América Latina. Curioso notar que os jovens de Cuiabá $(17,2 \%)$ possuem mais interesse por essa temática do que os jovens de Cáceres (9,3\%), município mais próximo da fronteira.

Analisando qualitativamente os dados obtidos, observa-se pouco interesse dos alunos mato-grossenses pelo estudo pela História Regional, e também de outros países da América Latina, o que acaba por mitigar a hipótese previamente lançada, de que os habitantes de uma região fronteiriça teriam maior interesse por essas temáticas. 
No gráfico abaixo observa-se o interesse dos jovens pela história dos seguintes lugares:

Gráfico 5 - Respostas dos estudantes à questão 18. Qual seu interesse pela história dos seguintes lugares, em porcentagens

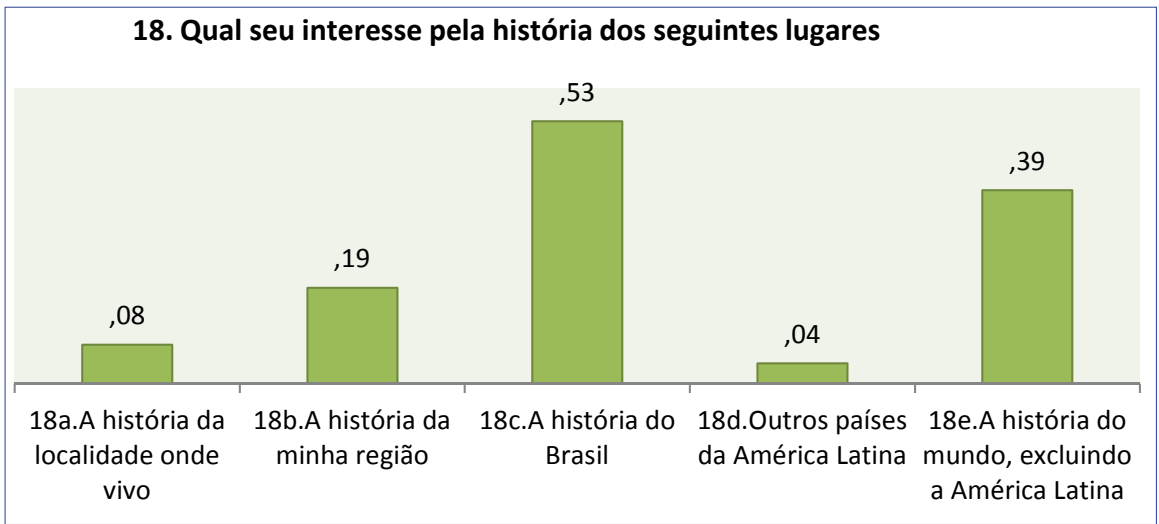

Fonte: Projeto Jovens e a História (2013). Elaboração dos autores.

Observando os dados do gráfico 5, podemos inferir que há maior interesse pela história do Brasil (53\%) e do mundo, excluindo a América Latina (39\%). Tal fenômeno evidencia o pouco interesse pela história da localidade onde os jovens vivem (08\%), sua região (19\%) e outros países da América Latina (04\%).

Elza Nadai (1993), em clássico artigo sobre a história do ensino de História no Brasil, localiza o nascimento da disciplina escolar de História no colégio D. Pedro II, no Rio de Janeiro, no ano de 1838. Filha da tradição francesa, a disciplina inicialmente configurou-se através das traduções dos compêndios franceses e da centralização no estudo da Europa Ocidental, dando pouco espaço para a História nacional. Somente com a Proclamação da República, em 1889, o ensino ganhou caráter fortemente nacionalista.

Naquele contexto, a concepção de História repousava "nas representações que procuravam expressar as ideias de nação e de cidadão embasadas na identidade comum de seus variados grupos étnicos e classes sociais constitutivos da nacionalidade brasileira" (NADAI, 1993, p. 149). Com isso, procurou-se criar uma ideia de nação totalizadora das raças. 
Vinculada ao conceito de progresso, a disciplina dedicava-se à civilização europeia ocidental, buscando identificar o Brasil a este bloco de países, principalmente a França. Desta forma, apesar de certa resistência de alguns profissionais da História, a América Latina manteve-se esquecida dos currículos.

Katia Abud (1998) observa que, "logo após a Revolução de 30 e a reorganização do Ministério da Educação e Saúde Pública, o então Ministro da Educação do Governo Provisório, Francisco Campos, comandou uma profunda modificação no sistema de ensino do país" (ABUD, 1998, p. 32).

Os programas e orientações metodológicas da Reforma Francisco Campos foram produzidos por comissões de especialistas que faziam parte de órgãos educacionais, sendo até hoje desconhecidos os nomes daqueles que formularam a proposta de História. Essa proposta abrangia a História Geral, do Brasil e da América de maneira a integrá-las na chamada História da Civilização.

A História da Civilização substituiu as antigas cadeiras de História Universal e História do Brasil, sendo o conteúdo integrado entre a chamada História Universal e a História do Brasil. O objetivo era "estabelecer uma estreita vinculação entre o estudo do passado nacional e americano com o passado europeu" (CASTRO, 1955 apud ABUD, 1993, p. 170). A História do Brasil e da América deveriam ser ensinadas de forma fragmentada, como reflexo da História europeia.

Apenas em 1942, o conjunto de decretos que ficou conhecido como Reforma Gustavo Capanema reestabeleceu o caráter autônomo da História do Brasil, aumentando, inclusive, a sua carga horária. A História da América só começa a aparecer nos currículos, com um espaço restrito, na década de 1950 ( ).

A recente polêmica envolvendo a produção da Base Nacional Comum Curricular (BNCC) permite observar permanências desse ranço eurocêntrico na história ensinada (RIBEIRO; RODRIGUES JUNIOR, 2017). A primeira versão, duramente criticada por apresentar uma perspectiva descolonizante, foi suplantada por uma terceira versão, que mantém o ensino de História eurocentrado. 
Os resultados da presente pesquisa permitem inferir que os currículos são fundamentais para o interesse ou desinteresse dos jovens estudantes por determinadas temáticas. A ausência da História da América dos currículos e da tradição escolar e a manutenção de uma perspectiva eurocêntrica corroboram para o pouco interesse dos jovens estudantes pela História Regional e dos demais países da América Latina, tendo em vista que eles não se sentem conectados aos hermanos latino-americanos.

Os resultados permitem, ainda, indagar de que forma os conteúdos sobre História Regional e História da América, ou a ausência deles, têm permitido aos jovens promoverem esses processos formativos. Isto demandaria um debate sobre os currículos, livros didáticos e demais materiais didáticos utilizados nas escolas públicas em Mato Grosso.

Na área de Ensino de História no Brasil, os debates e embates sobre o lugar do regional estão intimamente relacionados com as investigações direcionadas para a história local ${ }^{1}$. Para Maria Auxiliadora Schmidt (2007, p. 189), quando a aprendizagem histórica é pensada, precisa ser feita a seguinte questão: "por que trabalhar a história local?" Como respostas possíveis, a autora oferece as ideias de que a história local pode fornecer, aos estudantes, a busca da experiência do e no tempo, conforme defende Edward P. Thompson (1981), como critério para a seleção de conteúdos e a organização de temas históricos a serem ensinados e aprendidos a partir do princípio da formação da consciência histórica dos sujeitos (RÜSEN, 2009). Uma chave da compreensão das realidades locais estaria em sua relação com outras identidades locais, nacionais, latino-americanas e mundiais.

O universo dos alunos pesquisados, no caso de Mato Grosso, permite entender que o investimento dos professores de História e Geografia na história regional, pelo fato dos vestibulares das universidades públicas e privadas e concursos cobrarem esse tipo de conteúdo, não alterou significativamente o panorama de desinteresse dos jovens estudantes. Com a adesão das duas universidades públicas, UNEMAT e UFMT, ao Exame Nacional do Ensino Médio (ENEM), esse esforço tem sido ainda mais reduzido.

${ }^{1}$ Sobre o assunto, consultar a dissertação de mestrado de Jackson James Debona (2015), que buscou 
Por ser uma região de fronteira com a Bolívia, e ter uma história marcada pelas zonas de contato entre América Portuguesa e Espanhola no período colonial, Mato Grosso apresenta, em especial em Cuiabá e Cáceres, essas marcas sociais e culturais. Os cursos de formação de professores de História nessas cidades (UFMT/Cuiabá e UNEMAT/Cáceres) priorizaram, até o final dos anos 2010, conteúdos e fontes voltados para a História de Mato Grosso e História da América. No caso de Rondonópolis, onde também há um curso de Licenciatura em História no campus da UFMT, a temática da história regional era pautada na ênfase da localidade, ou seja, história da formação histórica da cidade, constituindo, por exemplo, a política de saída para capacitação dos professores em nível de pós-graduação².

Vale observar, também, que o Programa de Pós-graduação em História (PPGHIS) da UFMT, em Cuiabá, lócus de formação continuada de professores para o mestrado acadêmico, até a sua reestruturação, em 2010, para abertura do curso de doutorado, priorizava pesquisas sobre a história e historiografia de Mato Grosso, em interface com questões da História do Brasil e da América (GARCIA, 2003; JESUS, 2012; PERARO et al, 2011, AMEDI, 2012).

Contudo, observa-se que os esforços de inclusão das temáticas e de formação de professores para o trabalho com essas temáticas parecem não ter surtido, ainda, efeitos na prática docente. Assim, percebe-se o pouco interesse dos jovens estudantes de Mato Grosso pela História Regional e dos demais países da América Latina.

Concluindo, defendemos que esse interesse deve ser estimulado pelos processos formativos, que permitam aos educadores tratarem dos conteúdos de História Regional e da América, na direção de possibilitar uma aprendizagem histórica que permita mudanças estruturais na consciência histórica dos jovens, resultando em uma formação histórica que possibilite o reforço identitário, pois “(concretamente: todo sujeito nasce

\footnotetext{
${ }^{2}$ Partilhando dessa preocupação, Marcos Lobato Martins (2009, p. 143) conceitua a História Regional como aquela em que se "toma o espaço como terreno de estudo, que enxerga as dinâmicas históricas no espaço e através do espaço, obrigando o historiador a lidar com processos de diferenciação de áreas. A História Regional é a que vê o lugar, a região e o território como natureza da sociedade e da história, e não apenas como palco imóvel onde a vida acontece. Ela é História Econômica, Social, Demográfica, Cultural, Política etc., referida ao conceito chave de região".
} 
na história e cresce nela). O que o sujeito precisa é assenhorar-se de si a partir dela" (RÜSEN, 2007, p. 107).

\section{REFERÊNCIAS}

ABUD, Katia. O ensino de História como fator de coesão nacional: os programas de 1931. Revista Brasileira de História. São Paulo, n. 25/26, p. 163-174, set. 1992/ago. 1993.

. Formação da alma e do caráter nacional: ensino de história

na Era Vargas. Revista Brasileira de História. São Paulo, v. 18, n. 36, p. 103$114,1998$.

AMEDI, Nathália da Costa. A escrita da cidade: Cuiabá como objeto historiográfico. Revista Eletrônica Documento/Monumento. Cuiabá, v. 6, p. 73-86, 2012.

ANGVIK, Magne; BORRIES, Bodo von (eds.) Youth and History. A comparative European survey on historical consciousness and political attitudes among adolescents. Hambourg: Edition Körber-Stiftung, 1997. Vol. A.

ARIÈS, Philippe. A história marxista e a história conservador. In: O tempo da História. Rio de Janeiro: Francisco Alves, 1989, p. 30-47.

ARON, Raymond. Dimensiones de la Consciencia Historica. Madrid: Editorial Tecnos, 1962.

BAROM, Wilian C. C. As publicações do projeto Jovens e a História - 20072014. História \& Ensino. Londrina, v. 22, n. 1, p. 71-90, jan./jun. 2016.

BENJAMIN, Walter. Obras escolhidas, vol. 1. São Paulo: Brasiliense, 1985.

CARDOSO, Fernando Henrique. Desenvolvimento e identidade latinoamericana. Nossa América, Revista Memorial da América Latina. São Paulo, n. 23, 2006.

CERRI, Luís Fernando. Ensino de história e consciência histórica: implicações didáticas de uma discussão contemporânea. Rio de Janeiro: Ed. FGV, 2011. 
DEBONA, Jackson James. Entre o regional e o nacional: Mato Grosso do Sul nos livros didáticos de História - PNLD 2011. Dissertação (Mestrado em História) - Universidade Federal de Mato Grosso, Cuiabá, 2015.

GADAMER, Hans-Georg. Problemas epistemológicos das ciências humanas. In: FRUCHON, Pierre (Org.). O problema da consciência histórica. Rio de Janeiro: Editora da FGV, 1998.

GARCIA, Romyr Conde. Mato Grosso (1800-1840): crise e estagnação do projeto colonial. Tese (Doutorado em História Econômica) - Universidade de São Paulo, São Paulo, 2003.

HARTOG, François. Regimes de historicidade: presentismo e experiências do tempo. Belo Horizonte: Autêntica, 2014.

HELlER, Agnes. Uma teoria da História. Rio de Janeiro: Civilização Brasileira, 1993.

JESUS, Nauk Maria de. A capitania de Mato Grosso: história, historiografia e fontes. Revista Territórios e Fronteiras. Cuiabá, vol. 5, n. 2, p. 93-113, jul. dez. 2012.

MARTINS, Marcos Lobato. História Regional, In: PINSKY, Carla Bassanezi (Org.). Novos temas nas aulas de história. São Paulo, Contexto, 2009, p. 135-152.

NADAI, Elza. O ensino de História no Brasil: trajetórias e perspectivas. Revista Brasileira de História. São Paulo, n. 25/26, p. 143-162, set. 1992/ ago. 1993.

PERARO, Maria Adenir; BORGES, Fernando Tadeu de Miranda; JOANONI NETO, Vitale. Notas sobre a produção historiográfica acadêmica de Mato Grosso. In: GLEZER, Raquel (Org.). Do passado para o futuro: edição comemorativa dos 50 anos de ANPUH. São Paulo: Contexto, 2011, p. 145-166.

RIBEIRO, Renilson Rosa; RODRIGUES JUNIOR, Osvaldo. O labirinto das identidades no Brasil: Currículo(s) de História para os anos iniciais do Ensino Fundamental. In: RIBEIRO JÚNIOR, Halferd Carlos; VALÉRIO, 
Mairon Escorsi (Org.). Ensino de História e Currículo: reflexões sobre a Base Nacional Comum Curricular, formação de professores e prática de ensino. Jundiaí: Paco Editorial, 2017, p. 83-112.

RÜSEN, Jörn. Razão histórica. Brasília: Editora da Universidade de Brasília, 2001.

. História Viva. Brasília: Editora da Universidade de Brasília,

2007.

- ¿Que es la cultura historica? Reflexiones sobre una nueva manera de abordar la historia. [s.l.], [s.n.], 2009. . Jörn Rüsen e o ensino de História. Curitiba: Ed. UFPR, 2010. . Aprendizagem histórica: fundamentos e paradigmas. Curitiba: W.A Editores, 2012.

SADER, E. Introdução. In: SADER, E.; JINKINGS, I.; MARTINS, C. E.; NOBILE, R. (Coords.). Latinoamericana: enciclopédia contemporânea da América Latina e do Caribe. São Paulo: Boitempo, 2006. p. 29-32.

SCHMIDT, Maria Auxiliadora. O ensino de história local e os desafios da formação da consciência histórica. In: MONTEIRO, Ana Maria; GASPARELLO, Arlette M.;

MAGALHÃES, Marcelo S. (Org.). Ensino de história: sujeito, saberes e práticas. Rio de Janeiro: Mauad X; FAPERJ, 2007, p. 187-198.

THOMPSON, Edward P. A miséria da teoria ou um planetário de erros: uma crítica ao pensamento de Althusser. Rio de Janeiro: Jorge Zahar Ed., 1981. 